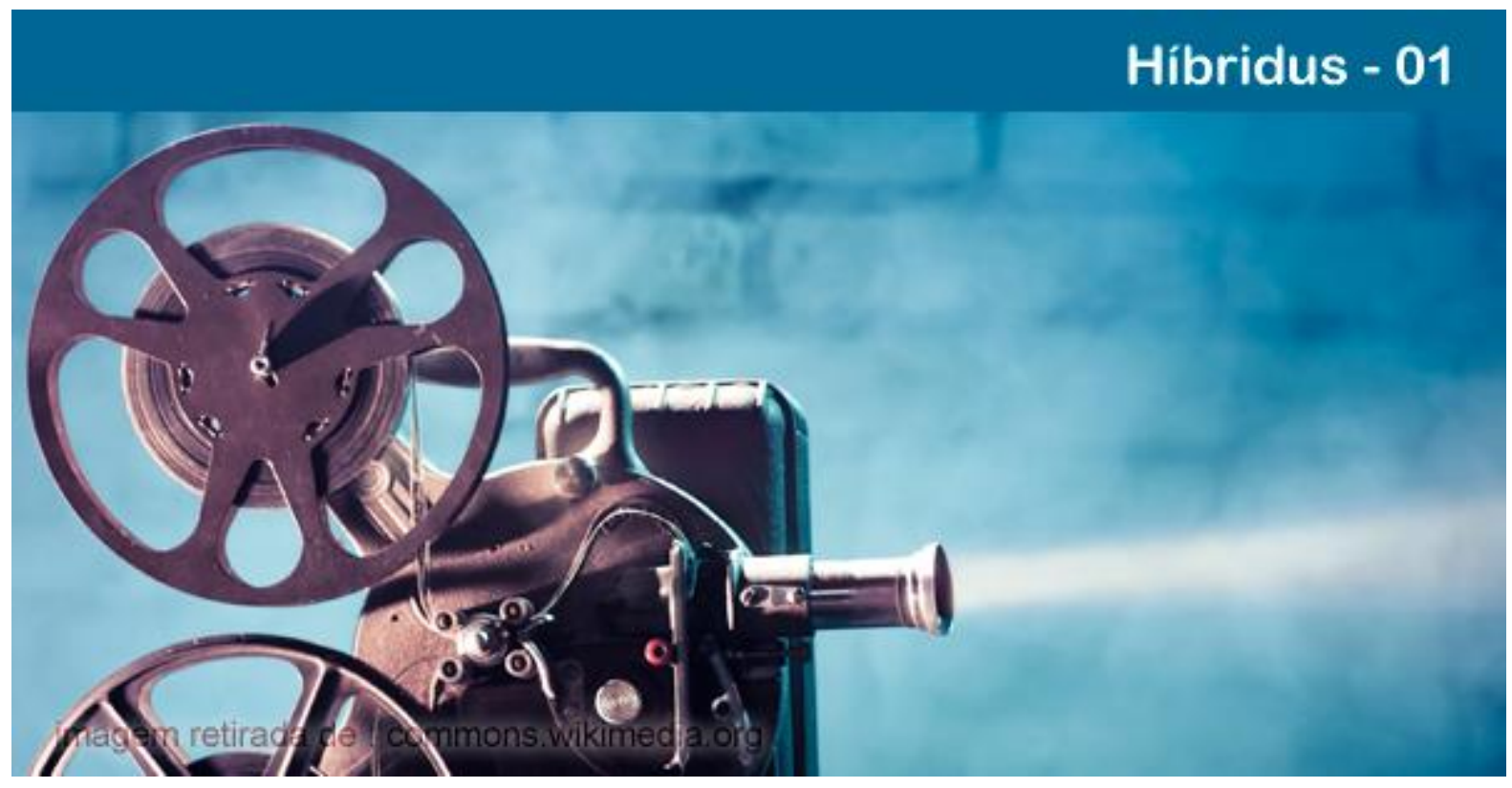

\title{
TÁTICAS DO CINEMA DE GUERRILHA DA BAIXADA PARA TRANSITAR ENTRE O POPULAR E O ARTÍSTICO
}

\section{Liliane Leroux}

Doutora em Educação e Pós-doutora em Cultura em Periferias Urbanas pela Universidade do Estado do Rio de Janeiro (UERJ). Professora e pesquisadora da UERJ. E-mail: liliane@leroux.pro.br.

Resumo: Neste texto, retomo aspectos do estudo de caso que realizei com o Cinema de Guerrilha da Baixada na virada de 2015 para 2016, como parte do mapeamento da produção audiovisual da Baixada Fluminense. Partindo do princípio de que 'cinema de guerrilha' não significa apenas fazer filmes com poucos recursos ("com o que se tem”), mas também, e sobretudo, a fabricação de um repertório de táticas capazes de potencializar esses recursos, evidencio algumas dinâmicas que configuram a "guerrilha" imanente ao grupo estudado. Além dos recursos financeiros modestos ou por vezes inexistentes que caracterizam estas produções, fazer filmes "com o que se tem" significa fabricar alternativas a partir de um contexto de não especialização e de escassez de tempo livre fora do trabalho diário com o qual se ganha (ou melhor dizendo, se perde) a vida.

Palavras-chave: Cinema de Guerrilha da Baixada. Cinema em periferias urbanas. Arte outsider. Popular e artístico.

\section{GUERRILLA CINEMA TACTICS FROM THE BAIXADA TO TRANSIT BETWEEN THE POPULAR AND THE ARTISTIC}

Abstract: In this text, I resume aspects from the case study I performed with the Cinema de Guerrilha da Baixada on the turning of 2015 to 2016, as part of an effort to map audio-visual production in the Baixada Fluminense. Starting from the notion that "guerrilla cinema" means not only making movies with limited resources ("with what is on hand"), but also, and foremost, the creation of a repertoire of tactics that can be used to multiply the potential of those resources, I put on evidence some of the dynamics that configure the "guerrilla" inherent to the studied group. Beyond the modest, or sometimes inexistent, budget that characterizes these productions, making movies with "what is on hand" means fabricating alternatives from a context of nonspecialization and absence of time besides the daily working hours with which a living is made (or lost).

Keywords: Cinema de Guerrilha da Baixada. Cinema in the urban peripheries. Outsider art. Popular and artistic.

I insist on a "guerrilla cinema" as the only form of combat: the cinema one improvises outside the conventional production against formal conventions imposed

\section{POLÊM!CA $\mid$ LABORE}

Polêmica - Revista Eletrônica da Uerj - Rua São Francisco Xavier, 524, $1^{\circ}$ andar

bloco D, sl.1001 • Tels.: +55 21 2334-4088/4087 • http://www.e-publicacoes.uerj.br/index.php/polemica/index http://www.labore.uerj.br • laboreuerj@yahoo.com.br 
on the general public and on the elite ${ }^{1}$.

(ROCHA, 1980, p. 80).

Cinema de guerrilha é um cinema sem recursos. O Vitor que teve essa ideia. Foi uma coisa da hora, bem cerveja de botequim.

(Ricardo Rodrigues, em entrevista concedida para a autora).

Eram cinco, na verdade seis, contando com a Thuainy: o açougueiro que tinha dois estabelecimentos perto da Igreja da Matriz, o dono da "birosca" na frente de casa, o jovem que filmava casamentos e trabalhava na lan house do irmão, o anão que vendia imã de geladeira. Tinha também o Paulo Ricardo, que trabalhava com teatro e hoje mora na Califórnia. E a Thuainy, uma menina ainda, que sonhava ser atriz.

Estamos em São João de Meriti, Baixada Fluminense, periferia urbana do estado do Rio de Janeiro. Ensombrada pela "cidade maravilhosa" vizinha, São João de Meriti, assim como os demais municípios da periferia fluminense, é local de múltiplas segregações: geográfica, social, econômica e cultural. O ano é 2010. Na Baixada, como em qualquer outro lugar do mundo, grande parte dos bons encontros artísticos e suas obras nascem na mesa de um bar. Nesta história não será diferente. O açougueiro, que se chama Ricardo Rodrigues, nas horas vagas era também escritor. Escreveu um conto baseado em um fato real que aconteceu em seu açougue e achou que daria um filme. Pagou três mil reais a uma produtora local e fez O Mendigo, convicto de que seria sua primeira e única aventura cinematográfica. Finalizou o filme em fevereiro, em março ganhou segundo lugar no Iguacine $^{2}$ e em agosto participou do festival da Cufa - Central Única das Favelas ${ }^{3}$ - sendo premiado com uma câmera caseira. Um dia, sentado com os outros amigos no bar, com a câmera que ganhara no festival na mão, um inseto cai no copo de cerveja de um deles.

- "Vai dar um curta. Vou filmar essa abelha aqui", disse o jovem que filmava casamentos, cujo nome completo é Vitor Gracciano.

Em seguida, pegou a câmera e fez o primeiro curta do Cinema de Guerrilha da Baixada, o CGB, que hoje conta com 52 filmes, 328 participações em festivais e mostras de cinema no Brasil e no exterior, 35 prêmios, além de veiculações em canais de TV.

\footnotetext{
${ }^{1}$ Tradução: Eu insisto em um "cinema de guerrilha" como a única forma de combate: o cinema no qual se improvisa fora da produção convencional, contra as convenções formais impostas ao público geral e na elite.

${ }^{2}$ Festival promovido desde 2008 pela Escola Livre de Cinema de Nova Iguaçu.

${ }^{3}$ IV Festival de Cinema Internacional da CUFA. Este e outros festivais serão discutidos um pouco mais adiante.
}

\section{POLÊM!CA $\mid$ LABORE}


Neste texto, retomo alguns aspectos do estudo de caso que realizei ${ }^{4}$ com o CGB na virada de 2015 para 2016, como parte do mapeamento da produção audiovisual da Baixada Fluminense que venho desenvolvendo 5 . Partindo do princípio que "cinema de guerrilha" não significa apenas fazer filmes com poucos recursos ("com o que se tem"), mas também, e sobretudo, a fabricação de um repertório de táticas capazes de potencializar esses recursos, quis evidenciar algumas dinâmicas que configuram a "guerrilha" imanente ao grupo estudado. Além dos recursos financeiros infinitamente modestos ou por vezes inexistentes que caracterizam estas produções, fazer filmes "com o que se tem" significa fabricar alternativas a partir de um contexto de não especialização e de escassez de tempo livre fora do trabalho diário com o qual se ganha (ou melhor dizendo, se perde) a vida.

Como o assunto é "guerra", é quase impossível não citar o estrategista prussiano Carl Von Clausewitz, que apesar de ter escrito seu livro Vom Kriege (Da Guerra) em 1832, é referência constante não só em teorias bélicas, mas também em análises sobre táticas midiáticas urbanas contemporâneas. Ao refletir sobre guerrilha, Clausewitz a define como a tática do homem comum que se arma para defender seu território contra um inimigo infinitamente superior a ele em diversos aspectos. Inspirada por esta caracterização, organizei o relato que apresento aqui.

\section{A guerrilha do homem comum - o açougueiro, o dono do bar e seus duplos}

Ricardo Rodrigues é filho de imigrantes portugueses que, como tantos outros, vieram para o Brasil fugindo da ditadura salazarista e iniciaram aqui seus pequenos negócios. Ricardo seguiu e atualizou o ofício do pai, tripeiro ${ }^{6}$, tornando-se um açougueiro. Seguiu o caminho aberto pela família, mas seu sonho era ser poeta e escritor. Chegou a escrever para políticos locais e para o jornal A Voz de Meriti. É também fundador da Academia de Letras e Artes de São João de Meriti e participou de uma coletânea de contos em 2005 que incluía Luis Fernando Veríssimo, Carlos Drummond de Andrade e Mário Quintana, entre outros.

\footnotetext{
${ }^{4} \mathrm{O}$ estudo de caso foi conduzido por mim dentro do NuVISU - Núcleo de Estudos Visuais em Periferias Urbanas (CNPq/UERJ) e contou com a participação de Tadeu Lima, graduando em Geografia e assistente de pesquisa, e de Lucia Marapodi, bolsista PROATEC.

${ }^{5} \mathrm{O}$ mapeamento da produção audiovisual da Baixada Fluminense é uma pesquisa que coordeno dentro do NuVISU - Núcleo de Estudos Visuais em Periferias Urbanas (CNPq/UERJ) com o apoio de 4 bolsistas pesquisadores, alunos do curso de Geografia da FEBF/UERJ: Tadeu Lima, Antonio Augusto Peres, Laís Seabra e Arthur Monteiro.

${ }^{6}$ Vendedor de tripas de vaca.
}

\section{POLÊM!CA $\mid$ LABORE}


José Ulivan Alves de Oliveira, o J. Ulivan, além de dono de bar, é compositor de samba "da antiga", com carteirinha que faz questão de mostrar. Inclusive, o primeiro encontro entre ele e Ricardo aconteceu na parceria de uma letra e música. Filiado à União Brasileira de Compositores - UBC e à antiga Federação de Blocos Carnavalescos do Estado da Guanabara, J. Ulivan foi o último parceiro do sambista Bebeto di São João. Por isso, a sua estreia no cinema se deu frente às câmeras como entrevistado junto com Dicró, Elza Soares e Nonato, no filme $O$ Guerreiro do Samba - a história de Bebeto di São João ${ }^{7}$ com direção de Jocemir Ferreira $^{8}$, que estreou no Odeon em 2010, durante o IV Encontro de Cinema Negro Brasil, África e Caribe, promovido pelo Centro Afro Carioca de Cinema de Zózimo Bulbul.

A música popular, especialmente o samba, tem sido historicamente a via mais comum e aceita através da qual alguém de origem simples ingressa no campo artístico. No campo literário, esta inserção fica um pouco mais difícil. Com certa dificuldade, é possível elencar alguns poucos escritores de classes menos favorecidas que lograram algum reconhecimento e prestígio: Orestes Barbosa, Antônio Fraga, João Antônio e Carolina de Jesus, entre outros. Mas, mesmo assim, o fato de um açougueiro ser também poeta e músico ou de um jovem de periferia ser compositor de samba não chega a causar grande estranhamento - que resolvam fazer filmes, isso sim é um fenômeno mais recente.

O cinema, especialmente o brasileiro, sempre esteve marcado por um forte elitismo. Ter acesso aos meios de produção de filmes exigia uma boa quantidade de dinheiro. Inicialmente, era necessário estudar em poucos e caros cursos de formação, na maioria das vezes fora do país. A produção dos filmes, por sua vez, dependia de uma estrutura grande e onerosa e de uma rede bem construída de conhecidos, amigos ou "padrinhos" que possibilitassem acesso ao financiamento. Raríssimos são os relatos de diretores que chegaram ao público sem a mobilização de vastos recursos próprios ou provenientes de um círculo social abastado ao qual, na maioria das vezes, já tinham acesso por nascimento.

$\mathrm{O}$ acesso popular em escala visível às competências e aspirações relacionadas à atividade cinematográfica surge agora, na virada do século, com a incorporação de tecnologias audiovisuais mais baratas e simples no cotidiano de um número cada vez maior de

\footnotetext{
${ }^{7}$ Guerreiro do Samba, filme, Jocemir Ferreira, 14'51”, Brasil.

${ }^{8}$ Cineasta nascido e criado no morro da Lagartixa, uma das favelas do complexo situado em Costa Barros, bairro localizado entre Pavuna, Anchieta, Guadalupe, Barros Filho, Coelho Neto e Acari. Falecido em abril de 2015. Estudou Cinema em Cuba com bolsa da Fundação W.T. Kellogg. Criador do Espaço Cultural Don Pixote e Espaço Cultural "Brincando de fazer arte" (luz câmera, ação e esperança na vida).
}$$
\text { POLÊM!CA | LABORẸ }
$$ 
pessoas, inclusive as de baixa renda. A proporção desse acesso fica evidente não apenas pela quantidade de vídeos de toda sorte que proliferam nas redes sociais inserindo a imagem como forma comum de comunicação, mas também pela produção e circulação crescente de filmes feitos com intenção cinematográfica, porém fora de esquemas especializados e institucionais. Por facilitar também o acesso à fruição de fílmes - desde os grandes clássicos até os vídeos caseiros -, aliado à possibilidade de falar sobre eles em redes amplas, o novo cenário tecnológico inaugura um movimento de autoformação do olhar e de aprendizado técnico a partir do qual surge uma nova geração de produtores audiovisuais vindos de classes sociais menos favorecidas e lugares distantes dos grandes centros de cultura. Os integrantes do Cinema de Guerrilha da Baixada, por exemplo, são todos fortemente autodidatas, do tipo "vai fazendo, vai aprendendo”, na expressão deles próprios. O único curso que Ricardo Rodrigues fez foi de roteiro, com Walcy Carrasco ${ }^{9}$. Victor, inicialmente, fez um curso bem básico de vídeo oferecido gratuitamente por uma ONG em Costa Barros. Apenas agora, seis anos após o início de sua atividade cinematográfica, ingressou na Escola de Cinema Darcy Ribeiro ${ }^{10}$. Da mesma forma, depois de vários filmes e algumas premiações de "melhor atriz", Thuainy começou a cursar Artes Cênicas com uma bolsa na PUC-RJ. Consideram que a prática é sua formação efetiva ou, de forma bem-humorada, que tenham alguma tendência inata, como J. Ulivan quando brinca ao afirmar que "já nasceu atuando".

O estímulo ao "faça você mesmo o seu filme" (que envolve formação, produção e distribuição) presente no contexto tecnológico atual desloca, em alguma medida, pesquisas anteriores (BECKER, 1982; DUBIN, 1997; FINE, 2004) que, referindo-se à entrada de outsiders no mundo das artes, situam no ato de "ser descoberto" a única - e ainda passiva alternativa a permanecer desconhecido. A pesquisa de campo que realizamos, e que narro neste artigo, mostra como os realizadores das periferias vem constituindo e conquistando modos e espaços próprios de formação, produção e exibição. Porém, quando a visibilidade alcançada por estes outsiders ${ }^{11}$ autodidatas vindos das periferias, que insistem em fazer arte, desperta o interesse da mídia ou de instituições dos grandes centros da cultura mainstream, as

\footnotetext{
${ }^{9}$ Dramaturgo, autor de novelas da Rede Globo de Televisão.

${ }^{10}$ Escola de cinema sem fins lucrativos fundada por Irene Ferraz com apoio de Darcy Ribeiro, Oscar Niemeyer, Nelson Pereira dos Santos, Cacá Diegues, Walter Lima Jr., Marieta Severo, Vilma Lustosa, Moacyr Werneck, Ana Lúcia Magalhães Pinto, João Luiz Vieira, Clóvis Brigagão e Alfredo Renault.

${ }^{11}$ Heinich (1997) define 5 diferentes significados para a ideia de insider/outsider no campo da arte. Um deles diz respeito à oposição geográfica entre artistas do centro e da periferia.
}

\section{POLÊM!CA $\mid$ LABORE}


interações ocorrem quase sempre na forma de um jogo ${ }^{12}$ que, se lhes abre uma via, ao mesmo tempo recria novas formas para velhas hierarquias.

Vejamos três episódios na trajetória de Ricardo. O primeiro ainda no terreno da literatura. No lançamento da coletânea em que participou, ele foi apresentado pelo editor ao escritor Luiz Fernando Veríssimo como "o açougueiro" e não, simplesmente, como coautor. Qual seria a razão para destacá-lo como açougueiro se é fato bastante comum escritores possuírem profissões paralelas para garantir seu sustento?

O segundo episódio ocorreu anos mais tarde, quando o Cinema de Guerrilha da Baixada começava a chamar a atenção da imprensa. A primeira matéria de jornal destaca "o açougueiro que faz filmes". E assim foi a segunda, a terceira, a quarta... Ao todo foram aproximadamente uma centena de reportagens com o mesmo tema em jornais e televisão. Por qual razão seria ainda tão importante identificá-lo como açougueiro?

Há uma passagem no belo livro de Jacques Rancière, A Noite dos Proletários, que narra a troca de correspondências entre um poeta, que tinha como principal ofício a alfaiataria, e Victor Hugo, escritor que dispensa apresentações. Na carta de "incentivo" ao poeta iniciante, Victor Hugo despede-se assim: "Continue; seja sempre o que você é, poeta e operário, isto é, pensador e trabalhador". Indignado com a sugestão do escritor, o primeiro retruca que o fardo de um alfaiate já consiste em tarefa para dois e que a verdadeira intenção de Victor Hugo é garantir que trabalhadores continuem a lhe servir, para que possa seguir levando a sua vida ociosa. Rancière, porém, arrisca que o temor de Victor Hugo teria menos relação com "a fartura de sua mesa do que com a raridade de seus versos". Ou seja, que a distinção a ser mantida a todo custo estaria antes na ordem do sensível: o trabalhador não pode, "na imagem do poeta, reconhecer em si nenhuma identidade", pois ele vive a verdade da qual só o poeta pode falar.

$\mathrm{Na}$ versão atual, a do açougueiro, tanto o editor como os jornais precisaram manter esta suposta divisão sensível. Enquanto os demais podem ser apenas escritores ou cineastas, preservar o açougueiro como aquele que faz duas coisas ao mesmo tempo é garantir que ele será sempre um imitador. Sob um discurso ainda mais sútil do que o de Victor Hugo, porém temperado com a mesma positividade enganadora, parece ser preciso ainda hoje apontar os

\footnotetext{
${ }^{12}$ Expressão adotada pelo sociólogo Bernard Lahire, em contraposição à ideia de "campo" (Bourdieu) ou "mundos" (Becker), para assinalar um espaço ainda pouco institucionalizado e no qual os agentes não estão inseridos de forma completa e permanente.
}

\section{POLÊM!CA $\mid$ LABORE}


imitadores. Mesmo que o açougueiro/cineasta seja retratado com simpatia ou até como um visionário, o que as entrelinhas dizem - principalmente em uma sociedade de superespecialização do trabalho como a nossa, na qual a formação é algo interminável - é que quem é açougueiro nunca será verdadeiramente cineasta, pois não se pode ocupar dois lugares ao mesmo tempo.

Foi Platão o primeiro a criar essa regulação (na forma de um mito), para que em seguida a sociologia (especialmente a de Bourdieu) a recriasse como ciência ${ }^{13}$. Evitar que duas coisas estejam em uma, que duas qualidades não pertençam ao mesmo ser, manter o alfaiate sempre como alfaiate e o açougueiro sempre como açougueiro, mesmo que façam poesias ou filmes, é parte de um jogo que atribui às ocupações o que na verdade se pretende manter como uma diferença de "naturezas" e, consequentemente, de destinos. No campo da arte, mesmo hoje, isso fica claro nas formas sempre renovadas de distinção entre profissionais e amadores, entre quem faz arte e quem faz cultura (popular): quem pode participar e em quais espaços, categorias, gêneros e condições.

Mas, vamos ao terceiro episódio, que relato de forma breve. Diz respeito ao modo como eles próprios perceberam que a distinção como "açougueiro" era um ativo que poderia gerar alguma vantagem. Como para os integrantes do CGB nunca houve distância entre a rudeza do trabalhador e a sensibilidade do cineasta, souberam reverter "o açougueiro" de estigma para persona, em total sintonia com a perspectiva contemporânea de arte e de artista, na qual a "obra" é também o modo todo autofabricado com o qual criador e criação aparecem para o mundo. A história do açougueiro/cineasta passou a lhes pertencer, e foi contada e recontada - agora por eles mesmos - em outras tantas reportagens. Até a última matéria, veiculada no jornal $O$ Dia, na qual Ricardo é fotografado dentro do freezer ligado e cheio de carnes de seu açougue, com uma claquete na mão. Apesar de terem gostado do teor do editorial, perceberam que estavam "cansados" da história do açougueiro e, deste dia em diante, as entrevistas passaram a focar em seus filmes e prêmios. Por já terem conquistado algum reconhecimento com seu trabalho, puderam abandonar de vez o mote.

Seis anos após o encontro inicial na mesa de bar, os membros do CGB continuam com suas profissões originais, que ainda garantem o sustento de suas famílias, mas, a partir da

${ }^{13}$ Ver Rancière (1983), Le Philosophe et ses pauvres.

\section{POLÊM!CA $\mid$ LABORE}


comprovação dos filmes que realizaram, todos conseguiram obter seus registros ${ }^{14}$ como atores e diretores profissionais.

\title{
A guerrilha e as táticas de infiltração
}

\begin{abstract}
Recentemente, tive acesso à obra surpreendente de Ricardo Rodrigues, um morador de São João de Meriti, cidade da Baixada Fluminense, que se apresenta como "açougueiro, cineasta e diretor do CGB (Cinema de Guerrilha da Baixada)". Ricardo é autor de curtas como Gigantes da Alegria e $O$ Evangelista, com mais de cem passagens por diferentes festivais alternativos. Sempre ligados a um campo temático de seu próprio mundo, seus filmes parecem reinaugurar gêneros como o thriller policial e a comedia de costumes, juntando e misturando tudo. (Cacá Diegues em capítulo intitulado Clandestinos de sua autobiografia Vida de Cinema - antes, durante e depois do Cinema Novo, p. 617 e 618).
\end{abstract}

Da abelha que caiu no copo de cerveja nasceu o curta Dona Irosnildes e Ricardo, que pretendia rifar a câmera e ganhar algum dinheiro com ela, resolveu fazer mais filmes com os amigos. Neste ponto da história entra o bar novamente, só que agora como cenário. A ideia foi fazer uma série: “Caramujo e seu pé sujo - doideiras e tonteiras num botequim”. J. Ulivan interpretou o personagem Caramujo e, desde então, este virou seu apelido e o novo nome de seu bar.

A maior parte dos filmes do CGB é rodada na pequena geografia entre a igreja da Matriz, o açougue, o viaduto, a ciclovia e o bar. Como a Lyon dos irmãos Lumière ou Berlin, Manhattan e Paris das City Symphonies dos anos 1920, também São João de Meriti passou a ser, quase que diariamente, desenhada com luz e movimento. No início, os moradores se assustavam, mas hoje todos já se acostumaram com o grupo filmando nas ruas e, muitas vezes, convocando a participação de quem passa. Seus filmes, nos poucos quarteirões que são seus cenários, nunca estão separados da cidade e suas muitas histórias. Isso encontra ressonância na observação do crítico Steven Shaviro (1993), para quem o cinema é, simultaneamente, a realidade reencontrada de um modo novo e uma parte da realidade, encontrada pela primeira vez. Um traço forte da guerrilha do CGB é estar aberto para o que acontece na cidade.

Muitos dos filmes do CGB assinados por Ricardo são sobre histórias que ouviu ou viu por ali mesmo, naqueles arredores. Os filmes assinados por J. Ulivan são todos gravados nos quarteirões próximos ao seu bar. Os atores são sempre eles mesmos e moradores de São João

\footnotetext{
${ }^{14}$ Refiro-me ao DRT - Registro de Artista e Técnico Cinematográfico, Lei nº 6.533/78.
}

\section{POLÊM!CA $\mid$ LABORE}


de Meriti, conhecidos, amigos, filho, entre outros tantos que são "laçados" na hora, conforme a intenção do roteiro que ele tenha na cabeça, pois nunca escreve uma linha sequer em uma folha de papel. A cidade como cenário, os amigos como atores, nada mais coerente, uma vez que é característica da guerrilha, não apenas o improviso, mas também uma certa "economia da dádiva"15,

O que surpreende é que, apesar de serem feitos com pessoas do lugar, a maior parte dos filmes está longe de qualquer fórmula que se aproxime ao documentário, entrevistas ou relatos. Pelo contrário, são ficções, ficções reais, com tudo o que o real tem de inacreditável, engraçado, ridículo, absurdo, triste e belo. Seus filmes retratam a vida, a dor e a graça daqueles quarteirões e dos que vivem por lá: o buraco na rua que vira lugar de pescaria, a cachaça e a cerveja como elementos sempre presentes, o arrependimento de uma mãe que abandona o filho, o homem vestido de diabo e a mulher de cigana em um dia real de carnaval que são transformados nestes personagens na tela, um jovem e suas aflições habituais dentro de seu apartamento, o drama de consciência de um trabalhador no conflito diário entre levar o salário para casa e seguir com a rotina ou gastar com mulheres, farra e bebida seja para esquecer da vida ou por pura vontade de reinventá-la. São filmes que, tomando emprestado de Kracauer, ganham força na sua trivialidade e na capacidade de retratar o simples e o cotidiano.

Se o processo de fazer os filmes "que dessem na cabeça" era espontâneo, livre, improvisado e despretensioso, o mesmo não acontecia com relação ao método de distribuição e exibição em festivais e mostras, levado a cabo com muita disciplina. Se a escassez de recursos não impediu a abundância de produções, a circulação e exibição - etapas mais difíceis para o cinema independente - demandaram outras táticas. Quando um festival recusava seus filmes, eles não desistiam e seguiam enviando para vários outros. Ricardo é o responsável pela parte de pesquisa - feita através de sites como o da Ancine ${ }^{16}$ ou o Porta $\operatorname{Curtas}^{17}$ - e envio de filmes para festivais desde 2010. Com este processo ganharam experiência, currículo, visibilidade, reconhecimento e, também, inúmeros contatos que

\footnotetext{
${ }^{15}$ Termo criado por Marcel Mauss para significar uma forma de organização social fundada na doação recíproca. Apesar de, originalmente, se referir às sociedades primitivas, tem sido largamente utilizado em análises mais atuais sobre redes.

${ }^{16}$ Agência Nacional do Cinema.

${ }^{17}$ Portal da internet com filmes curta metragens nacionais (http://portacurtas.org.br/Default.aspx).
}

\section{POLÊM!CA $\mid$ LABORE}


abriram outras portas. Hoje o CGB contabiliza 328 participações em festivais e mostras com uma taxa de retorno superior a $10 \%$ em premiações. O filme Gigantes da Alegria, por exemplo, como podemos ver na tabela abaixo, foi exibido em quase todo o Brasil através de 65 festivais.

Tabela - 1: Participações em Mostras e Festivais

\begin{tabular}{|c|c|c|c|}
\hline ANO & FILME & Participações & Premiações \\
\hline 2015 & O triste fim de Herivelton & 3 participações & \\
\hline 2015 & Noites sem Lua & 1 participação & 1 prêmio \\
\hline 2015 & D’água & & \\
\hline 2014 & O Perdão & 14 participações & 2 prêmios \\
\hline 2014 & Web-série: Vãobora & 1 participação & 1 prêmio \\
\hline 2014 & Falta Água & 11 participações & 1 prêmio \\
\hline 2014 & Paraíba Pede Socorro & 4 participações & 1 prêmio \\
\hline 2014 & Quero ir pra casa & 4 participações & \\
\hline 2014 & Onde é o banheiro? & 2 participações & \\
\hline 2014 & Insight & 2 participações & 3 prêmios \\
\hline 2013 & Salvem o Rio & 10 participações & \\
\hline 2013 & Tela Preta & 10 participações & \\
\hline 2013 & $220 \mathrm{~V}$ & 11 participações & \\
\hline 2013 & O Evangelista - documentário & 19 participações & \\
\hline 2013 & Sorriso de Farmácia & 1 participação & \\
\hline 2013 & Rosangela e Gabriel & 2 participações & \\
\hline 2012 & $\begin{array}{l}\text { Vozes do mundo de quem não } \\
\text { tem voz no mundo - } \\
\text { documentário }\end{array}$ & 3 participações & \\
\hline 2012 & Pesque e Pague & 23 participações & 1 prêmio \\
\hline 2012 & Gigantes da Alegria & 65 participações & 9 prêmios \\
\hline 2012 & Coisas de Mulher & 1 participação & \\
\hline 2012 & Falta ela & 33 participações & 4 prêmios \\
\hline 2011 & Enterro de Anão & 23 participações & 1 prêmio \\
\hline 2011 & A Dona Irosnildes & 7 participações & \\
\hline 2011 & Tá difícil & 4 participações & \\
\hline 2011 & Música em peso de primeira & 1 participação & \\
\hline 2011 & O nome da mãe & 8 participações & \\
\hline 2011 & $4 \times 1$ & 1 participação & \\
\hline
\end{tabular}

\section{POLÊM!CA LABORE}

Polêmica - Revista Eletrônica da Uerj - Rua São Francisco Xavier, 524, $1^{\circ}$ andar 


\begin{tabular}{|l|l|l|l|}
\hline 2010 & Falta 10 & 2 participações & \\
\hline 2010 & O Mendigo & 61 participações & 11 prêmios \\
\hline
\end{tabular}

Fonte: Preparada por Tadeu Lima a partir de materiais do CGB e dos festivais.

Participar de um festival implica, inicialmente, em uma pesquisa prévia e em enviar o filme no suporte determinado pelos organizadores. Nesta parte do processo o CGB já possui boa estrutura e experiência e, alguns meses, chegam a ter seus filmes exibidos em 5 festivais diferentes. Mas, filme aceito, nem sempre conseguem ir pessoalmente representar suas produções em outros estados ou países. Isso por dois motivos: nem todos os festivais pagam passagens e também pelo fato de muitas vezes não poderem se ausentar do trabalho diário que (ainda) garante suas rendas. Sem dúvida é um entrave, uma vez que, nas regras tácitas dos festivais, ter um representante presente, principalmente se o filme for de outro estado ou país, favorece em alguma medida a premiação.

O Cinema de Guerrilha da Baixada é um grupo muito ativo não apenas pela quantidade de produções, mas, sobretudo, pelo investimento pesado de tempo, esforço e inteligência em uma estratégia bem-sucedida de circulação e exibição através de mostras e festivais que descobriram e que deu certo. As tabelas abaixo retratam a circulação dos filmes do CGB por diferentes festivais e cidades do Brasil (Tabela 2) e do exterior (Tabela 3).

Tabela - 2: Circulação dos filmes pelo Brasil

\begin{tabular}{|c|l|l|}
\hline \multicolumn{2}{|c|}{ Circulação pelo Brasil em Festival } \\
\hline AM & Macapá & FIM - Festival de Imagem em Movimento \\
\hline \multirow{4}{*}{ BA } & Itacoacoara & I Mostra de Cinema Itinerante - Itacoacoara \\
\cline { 2 - 3 } & Salvador & $1^{\circ}$ Festival Transterritorial de Cinema Underground \\
\cline { 2 - 3 } & Salvador & XXXVII Festival de Cinema Internacional - Jornada da Bahia \\
\cline { 2 - 3 } & Porto Seguro & $5^{\circ}$ Arraial Cine Fest \\
\cline { 2 - 3 } & Porto Seguro & $6^{\circ}$ Arraial Cine Fest \\
\cline { 2 - 3 } & Porto Seguro & $5^{\circ}$ Festival de Cinema Internacional - Arraial Cine Fest \\
\cline { 2 - 3 } & Salvador & XVI Festival Nacional 5 minutos \\
\hline CE & Jericoacoara & II Festival de Cinema Digital Jericoacoara \\
\cline { 2 - 3 } & Jericoacoara & CINE JERI - 2014 - Festival de Cinema de Jericoacoara \\
\cline { 2 - 3 } & Maracanaú & III Fest. Cine Maracanaú \\
\cline { 2 - 3 } & Maracanaú & IV Fest. Cine Maracanaú \\
\cline { 2 - 3 } & Maracanaú & V Fest. Cine Maracanaú \\
\cline { 2 - 3 } & $\begin{array}{l}\text { São Gonçalo do } \\
\text { Amarante }\end{array}$ & I Fest Cine São Gonçalo \\
\hline \multirow{2}{*}{ DF } & Brasilia & $6^{\circ}$ Circuito Tela Verde \\
\cline { 2 - 3 } & Brasilia & Cineperiferia \\
\hline Diversos estados & $10^{\mathbf{a}}$ Mostra Cinema e Direitos Humanos no Mundo \\
\hline ES & Cachoeiro do & Cine.Ema \\
\hline
\end{tabular}

\section{POLÊM!CA $\mid$ LABORE}

Polêmica - Revista Eletrônica da Uerj - Rua São Francisco Xavier, 524, $1^{\circ}$ andar

bloco D, sl.1001 • Tels.: +55 21 2334-4088/4087 • http://www.e-publicacoes.uerj.br/index.php/polemica/index http://www.labore.uerj.br • laboreuerj@yahoo.com.br 


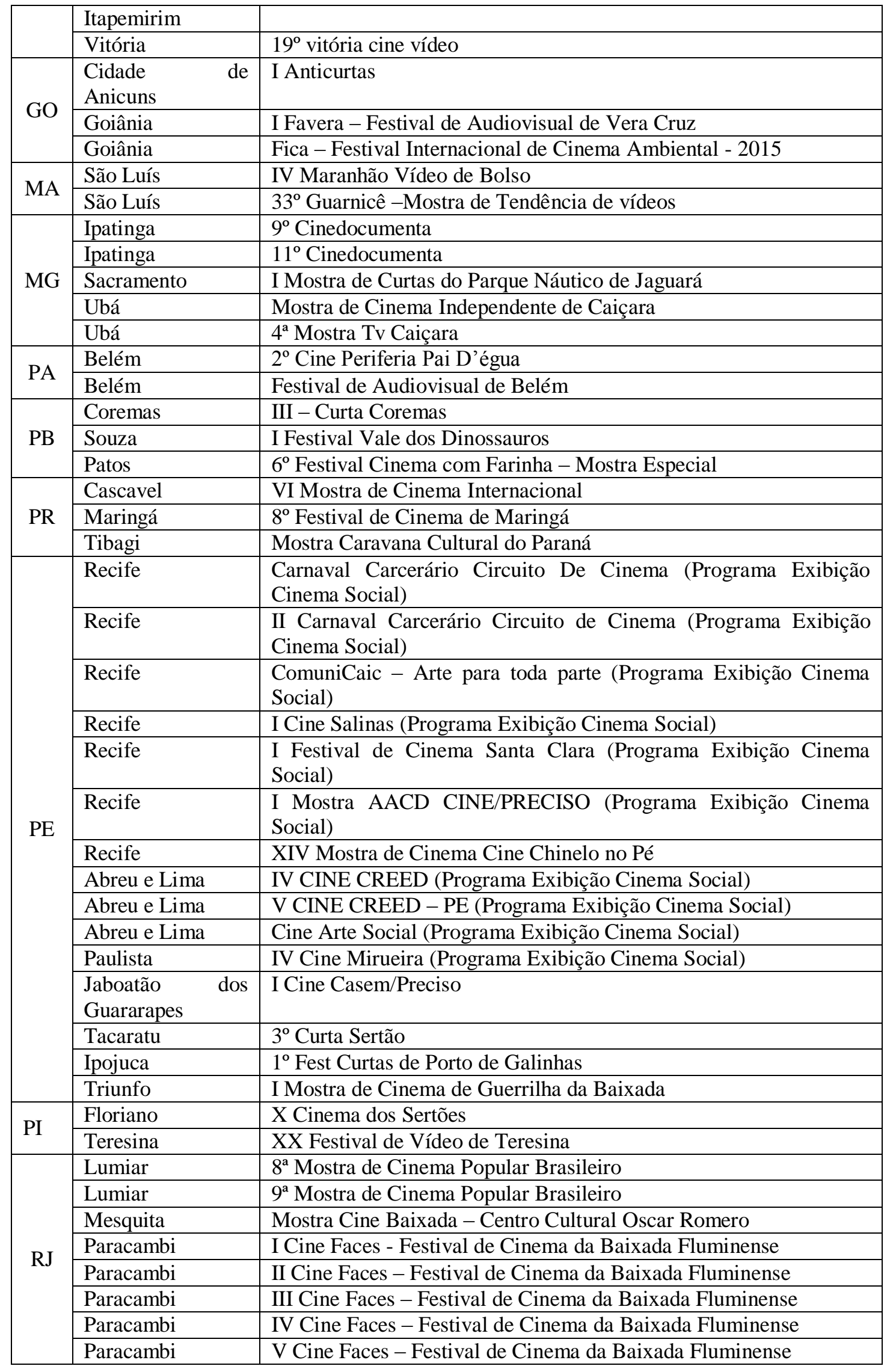

\section{POLÊM!CA LABORÉ}

Polêmica - Revista Eletrônica da Uerj - Rua São Francisco Xavier, 524, $1^{\circ}$ andar 


\begin{tabular}{|c|c|c|}
\hline & Queimados & Mostra Cine Marapicu \\
\hline & Belford Roxo & $4^{\circ}$ Cinerock \\
\hline & Cabo Frio & V Curta Cabo Frio \\
\hline & Cabo Frio & VI Curta cabo Frio \\
\hline & Cabo Frio & $8^{\circ}$ Festival Curta Cabo Frio \\
\hline & Diversas cidades & $3^{\circ}$ Curta Baixada (Nova Iguaçu, Caxias, São João de Meriti) \\
\hline & Duque de Caxias & Cinidebra \\
\hline & Duque de Caxias & Sessão Catapulta 2014 - Cineclube Mate com Angu \\
\hline & Duque de Caxias & $\begin{array}{l}\text { Festival Curta Caxias - Panorama Baixada (Cineclube Mate com } \\
\text { Angu) }\end{array}$ \\
\hline & Duque de Caxias & I Festival Curta Viva Caxias \\
\hline & Duque de Caxias & II Festival Curta Viva Caxias \\
\hline & Duque de Caxias & $\begin{array}{l}\text { UERJ/FEBF - Sessão “A imagem ao redor" - Seminário } \\
\text { Acadêmico - RJ }\end{array}$ \\
\hline & Macaé & $2^{\circ}$ Festival de Cinema Ambiental / UFRJ \\
\hline & Macaé & II Fest. Cine Macaé \\
\hline & Mangaratiba & $23^{\circ}$ Expo Cultural \\
\hline & Nilópolis & Semana Nacional de Ciencia e Tecnologia - IFRJ de portas abertas \\
\hline & Nova Friburgo & Mostra Curta na Serra - Coletivo Serra Elétrica \\
\hline & Nova Iguaçu & Encontrarte \\
\hline & Nova Iguaçu & I Baixada Encena \\
\hline & Nova Iguaçu & $\begin{array}{l}\text { I Mostra Cinema de Guerrilha da Baixada - Cineclube Buraco do } \\
\text { Getúlio }\end{array}$ \\
\hline & Nova Iguaçu & III Iguacine \\
\hline & Nova Iguaçu & IV Festival Iguacine \\
\hline & Paraty & $\begin{array}{l}\text { IX Fatu - Festival Brasileiro de Filmes de Aventura, Turismo e } \\
\text { Sustentabilidade }\end{array}$ \\
\hline & Petrópolis & I Festival de Cinema de Petrópolis \\
\hline & Petrópolis & $3^{\circ}$ Festival de Cinema de Petrópolis \\
\hline & Resende & Mostra NCR TV - TV Caiçara \\
\hline & Rio de Janeiro & $10^{\mathrm{a}}$ Mostra do Cinema Popular Brasileiro \\
\hline & Rio de Janeiro & MFL - Mostra do Filme Livre - 2015 \\
\hline & Rio de Janeiro & MFL - Mostra do Filme Livre - 2014 \\
\hline & Rio de Janeiro & MFL - Mostra do Filme Livre - 2013 \\
\hline & Rio de Janeiro & $2^{\mathrm{a}}$ Mostra Curta VK \\
\hline & Rio de Janeiro & $3^{\text {a }}$ Mostra Competitiva TV Caiçara \\
\hline & Rio de Janeiro & $6^{\circ}$ Festival Internacional Assim Vivemos \\
\hline & Rio de Janeiro & $7^{\mathrm{a}}$ Mostra William Juvêncio \\
\hline & Rio de Janeiro & $8^{\text {a }}$ Mostra Audiovisual William Juvêncio - Cinema Show \\
\hline & Rio de Janeiro & Cine Mateiro - PUC \\
\hline \multirow[t]{11}{*}{ RJ } & Rio de Janeiro & Cinema de Urgência - Oi Futuro - Curta Cinema \\
\hline & Rio de Janeiro & CINEstesia - Mostra de Cinema na Babilônia \\
\hline & Rio de Janeiro & Clima: somos todos responsáveis - Planetário \\
\hline & Rio de Janeiro & Curta na Uerj \\
\hline & Rio de Janeiro & Curta no Botequim \\
\hline & Rio de Janeiro & I Fest. TV Caiçara \\
\hline & Rio de Janeiro & II Mostra TV Caiçara \\
\hline & Rio de Janeiro & I Mostra de Cinema Independente de Caiçara \\
\hline & Rio de Janeiro & I Suburbaixada -RJ mostra de filmes do subúrbio e da BF \\
\hline & Rio de Janeiro & II Cine Curta Lapa \\
\hline & Rio de Janeiro & III Cine Curta Lapa \\
\hline
\end{tabular}

\section{POLÊM!CA $\mid$ LABORE}

Polêmica - Revista Eletrônica da Uerj - Rua São Francisco Xavier, 524, $1^{\circ}$ andar

bloco D, sl.1001 • Tels.: +55 21 2334-4088 / 4087 • http://www.e-publicacoes.uerj.br/index.php/polemica/index http://www.labore.uerj.br • laboreuerj@yahoo.com.br 


\begin{tabular}{|c|c|c|}
\hline & Rio de Janeiro & IV Curta Lapa \\
\hline & Rio de Janeiro & II Festival Brasileiro de Cinema Internacional (FBCI) \\
\hline & Rio de Janeiro & III Festival Brasileiro de Cinema Internacional (FBCI) \\
\hline & Rio de Janeiro & II Rio Mapping Festival \\
\hline & Rio de Janeiro & II Sarau Encanto - Biblioteca Nossa Casa \\
\hline & Rio de Janeiro & Vercine - Festival de Cinema Brasileiro da Baixada Fluminense \\
\hline & Rio de Janeiro & II Vercine - Festival de Cinema Brasileiro da Baixada Fluminense \\
\hline & Rio de Janeiro & IV Cinecufa - Festival de Cinema Internacional \\
\hline & Rio de Janeiro & Mostra Carta Branca - Subúrbio em Transe - Odeon \\
\hline & Rio de Janeiro & Mostra Subúrbio em transe \\
\hline & Rio de Janeiro & Mostra Ciclo Realizadores - Cine Nós do Morro \\
\hline & Rio de Janeiro & Mostra Cineclube Subúrbio em Transe \\
\hline & Rio de Janeiro & Mostra Cinema de Guerrilha da Baixada - Ponto Cine \\
\hline & Rio de Janeiro & Mostra Coletivo Criativo de Rua - Teatro a Rodo. \\
\hline & Rio de Janeiro & Mostra Curta no Botequim \\
\hline & Rio de Janeiro & Mostra de Cinema - Cinestesia na Babilônia \\
\hline \multirow[t]{18}{*}{ RJ } & Rio de Janeiro & Mostra Nuvem de Cinema \\
\hline & Rio de Janeiro & Projeto Academia vai a Escola - C.E. Murilo Braga \\
\hline & Rio de Janeiro & Projeto SESC "Fala Autor" - C.E. Murilo Braga \\
\hline & Rio de Janeiro & Visões Periféricas - 2014 \\
\hline & Rio de Janeiro & Visões Periféricas - Mostra Baixada - 2013 \\
\hline & Rio de Janeiro & Visões Periféricas - Mostra Especial - 2013 \\
\hline & Rio de Janeiro & Visões Periféricas - Mostra Cinema da Gema - 2013 \\
\hline & Rio de Janeiro & Visões Periféricas - 2012 \\
\hline & Rio de Janeiro & X Festival Primavera - Roda Viva - PUC \\
\hline & $\begin{array}{l}\text { São João de } \\
\text { Meriti }\end{array}$ & Curta Cinema - SESC \\
\hline & $\begin{array}{l}\text { São João de } \\
\text { Meriti }\end{array}$ & $\begin{array}{l}\text { I Flidamcine - Festival Literário Internacional da Diáspora Africana } \\
\text { em São João de Meriti }\end{array}$ \\
\hline & $\begin{array}{l}\text { São João de } \\
\text { Meriti }\end{array}$ & Mostra Cine Ideia - Dia Nacional da Cultura \\
\hline & $\begin{array}{l}\text { São João de } \\
\text { Meriti }\end{array}$ & I Mostra Meriti de Cinema Nacional \\
\hline & $\begin{array}{l}\text { São João de } \\
\text { Meriti }\end{array}$ & II Curta Meriti \\
\hline & $\begin{array}{l}\text { São João de } \\
\text { Meriti }\end{array}$ & II Mostra Sesc Meriti de Cinema Nacional \\
\hline & $\begin{array}{l}\text { São João de } \\
\text { Meriti }\end{array}$ & Mostra Cinema com Batuque - Sesc \\
\hline & $\begin{array}{l}\text { São João de } \\
\text { Meriti }\end{array}$ & Cineclube de Guerrilha da Baixada \\
\hline & Nova Iguaçu & Mostra Cinema de Guerrilha - Cine Clube Digital \\
\hline \multirow{7}{*}{$\mathrm{RS}$} & Guaíba & $10^{\circ}$ festival de vídeo infantil Guaíba - Mostra Alternativa \\
\hline & Guaíba & $12^{\circ}$ Festival de Vídeo Estudantil e Mostra de Cinema de Guaíba \\
\hline & Guaíba & $12^{\circ}$ Festival de Vídeo de Guaíba \\
\hline & Guaíba & XI Festival de Cinema e Video \\
\hline & Santa Maria & $11^{\circ}$ Santa Maria Video e Cinema \\
\hline & São Leopoldo & Curta Centenário - São Leopoldo \\
\hline & Três Passos & II Festival de Cinema de Três Passos \\
\hline \multirow{3}{*}{$\mathrm{RO}$} & Porto Velho & $10^{\mathrm{a}}$ Fest Cine Amazônia \\
\hline & Porto Velho & $12^{\circ}$ Fest Cine Amazônia \\
\hline & Porto Velho & Festival de Cinema de Rondônia - Mostra Curta Criança \\
\hline
\end{tabular}

\section{POLÊM!CA | LABORẸ}

Polêmica - Revista Eletrônica da Uerj - Rua São Francisco Xavier, 524, $1^{\circ}$ andar

bloco D, sl.1001 • Tels.: +55 21 2334-4088 / 4087 • http://www.e-publicacoes.uerj.br/index.php/polemica/index http://www.labore.uerj.br • laboreuerj@yahoo.com.br 


\begin{tabular}{|c|c|c|}
\hline & Porto Velho & $2^{a}$ Curta Amazônia - Mostra Infantil \\
\hline & Porto Velho & $3^{\text {a }}$ Curta Amazônia \\
\hline & Porto Velho & $4^{\circ}$ Festival de Cinema Curta Amazônia \\
\hline & Porto Velho & $9^{\circ}$ Fest Cine Amazônia - \\
\hline & Porto Velho & $11^{\circ}$ Fest Cine Amazônia \\
\hline & Porto Velho & $\begin{array}{l}\text { Festival Latino Americano de Cinema e Vídeo Ambiental - Mostra } \\
\text { Paralela - Acervo } 2011\end{array}$ \\
\hline $\mathrm{SC}$ & Florianópolis & TourFilmBrasil \\
\hline \multirow{13}{*}{ SP } & Joanópolis & $\begin{array}{l}\text { X Fatu - Festival Brasileiro de Filmes de Aventura, Turismo e } \\
\text { Sustentabilidade }\end{array}$ \\
\hline & São Paulo & I Festival de Cinema Leste em Movimento - Panorama Extra \\
\hline & Campinas & $1^{\mathrm{a}}$ Mostra Campinas de Filmes Políticos e Independentes \\
\hline & Campinas & $2^{\circ}$ Festival de Cinema Leste em Movimento \\
\hline & Campinas & $3^{\mathrm{a}}$ Mostra Luta \\
\hline & Campinas & Ecocine - Festival Internacional de Cinema Ambiental \\
\hline & Campinas & Mostra Curta Audiovisual \\
\hline & Indaiatuba & Take1 - Festival de cinema de Indaiatuba \\
\hline & Mogi Mirim & $1^{\circ}$ Festival de Cinema de Mogi Mirim \\
\hline & Ourinhos & $8^{\circ}$ Curta Ourinhos \\
\hline & São Carlos & I Mostra de Vídeo Popular de São Carlos \\
\hline & São Paulo & $9^{\circ}$ São Paulo Film Commission \\
\hline & São Paulo & Mostra de Cinemateca Nacional \\
\hline \multirow{3}{*}{ TO } & Miracema & V Mostra de Cinema Nacional \\
\hline & Miracema & VII Mostra Miracema \\
\hline & Miracema & $8^{a}$ Mostra Miracema \\
\hline
\end{tabular}

Fonte: Tabela preparada por Tadeu Lima a partir de materiais do CGB e dos festivais.

Tabela - 3: Circulação dos filmes pelo exterior

\begin{tabular}{|l|l|l|l|}
\hline \multicolumn{3}{|c|}{ Local } \\
\hline \multicolumn{3}{|c|}{ FESTIVAIS INTERNACIONAIS } \\
\hline Argentina & Itinerante (inicia em Tucumán) & Festival Cortados \\
\hline Brasil / Moçambique & $5^{\circ}$ Festival de Cinema Internacional Cine Cufa \\
\hline Colômbia & Bogotá & Bogotá & $29^{\circ}$ Festival de Cinema Internacional de Bogotá \\
\hline Espanha & \multicolumn{2}{|c|}{ (internet) } & V Edición - FIBABC \\
\hline EUA & Califórnia & Los Angeles & $5^{\circ}$ Festival de Cinema Brasileiro em Los Angeles \\
\hline EUA & Califórnia & Los Angeles & $6^{\circ}$ Festival de Cinema Brasileiro em Los Angeles \\
\hline EUA & Califórnia & Los Angeles & $7^{\circ}$ Festival de Cinema Brasileiro em Los Angeles \\
\hline México & Jalisco & Guadalajara & $11^{\circ}$ Mercado de Cine Iberoamericano en Guadalajara \\
\hline Peru & Lima & Lima & $\begin{array}{l}17^{\circ} \text { Festival Internacional de Cinema de Lima - Mostra } \\
\text { Itinerante }\end{array}$ \\
\hline Portugal & São Miguel & Ponta Delgada & Azores FilmFestival \\
\hline Portugal & Lisboa & Itinerante & $4^{\circ}$ FESTIN \\
\hline Portugal & Lisboa & Lisboa & $6^{\circ}$ Festival Imigrarte \\
\hline Portugal & Évora & Évora & FIKE - Festival Internacional de Cinema \\
\hline Portugal & Guarda & Seia & Cine Eco \\
\hline Portugal & Guarda & Seia & XVII Festival de Cinema Ambiental da Serra da Estrela \\
\hline Portugal & Lisboa & Lisboa & $\begin{array}{l}\text { Fest in - festival internacional de cinema itinerante - } \\
\text { Mostra Social }\end{array}$ \\
\hline
\end{tabular}

Fonte: Preparada por Tadeu Lima a partir de materiais do CGB e dos festivais.

\section{POLÊM!CA $\mid$ LABORE}

Polêmica - Revista Eletrônica da Uerj - Rua São Francisco Xavier, 524, $1^{\circ}$ andar

bloco D, sl.1001 • Tels.: +55 21 2334-4088/4087 • http://www.e-publicacoes.uerj.br/index.php/polemica/index http://www.labore.uerj.br • laboreuerj@yahoo.com.br 
Acompanhar este processo, lança luz em um outro fenômeno recente: a abertura de um número cada vez maior de festivais e mostras para filmes com formato, duração e produção fortemente alternativos.

Historicamente, os cineclubes são espaços privilegiados para a exibição de filmes de coletivos e de cineastas independentes e amadores. A Baixada Fluminense possui uma larga tradição de cineclubes, muitos bastante conhecidos em todo o estado e nacionalmente. Entre os ativos estão: Buraco do Getúlio (Nova Iguaçu), Mate com Angu (Caxias), Donana (Belford Roxo), Código (Japeri), Cine Marapicu (Queimados), Ankito (no IFRJ de Nova Iguaçu), Cineclube Digital (no SESC de Nova Iguaçu), Cineclube Velho Brejo (Belford Roxo), Cineclube Videoverso (Mesquita), Cineclube Ágora (Duque de Caxias), Cineclube Xuxucomxis (Nova Iguaçu), além, é claro, do Cineclube de Guerrilha, o CGB, que funciona no Bar do Caramujo (de J. Ulivan), em São João de Meriti. Os cineclubes são bastante respeitados, possuem calendários próprios de exibição e evitam conflitar com a data dos outros cineclubes ou de outros eventos culturais importantes ${ }^{18}$, além de possuírem um público fiel composto inclusive por moradores dos bairros mais nobres da cidade do Rio de Janeiro. É bastante comum que os cineastas da Baixada produzam seus filmes em associação com um cineclube local, também nos moldes da economia da dádiva. É possível observar como alguns cineclubes já constituíram uma marca adicional para destacar a atividade de produção de filmes. É o caso, por exemplo, do Cineclube Mate com Angu, que criou a Angu TV e finaliza suas produções com a legenda "Um filme Mate com Angu".

Para além dos cineclubes, ocorre atualmente no Brasil um circuito que conta com aproximadamente 240 festivais $^{19}$. O momento presente traz como novidade uma maior abertura dos festivais para novos formatos, categorias e gêneros. Se os principais festivais do país e do mundo já estão dando reconhecimento para os filmes independentes produzidos com baixo orçamento dentro do que vem sendo denominado - não sem críticas - de Novíssimo Cinema Brasileiro, a abertura de outros tantos festivais para filmes de curta (ou mesmo curtíssima) duração, filmes feitos com celular e outras tantas variações, vem abarcando as novas produções independentes realizadas a partir de um contexto de baixíssimo ou mesmo nenhum orçamento que cresce a cada dia.

\footnotetext{
${ }^{18}$ Sobre esta e outras especificidades da "Baixada Cultural", ver dissertação de mestrado de Leonardo Onofre (2016), sob minha orientação no PPG Educação, Cultura e Comunicação em Periferias Urbanas (UERJ).

${ }^{19}$ Disponível em: http://www.forumdosfestivais.com.br/\#!quem-somos/c1c32.
}

\section{POLÊM!CA $\mid$ LABORE}


Entre todos os que incentivam essas produções alternativas, destaco aqui, de forma breve, a importância de um deles para os cineastas das periferias do país que fazem seus filmes "na guerrilha". Refiro-me à Mostra do Filme Livre - MFL, surgida em 2002 e, atualmente, considerada o maior espaço de distribuição e exibição de filmes altamente independentes $^{20}$. Por ser extremamente aberta, a MFL é o maior panorama dos filmes alternativos brasileiros. Para a seleção de sua edição de 2016, recebeu 1.322 filmes de todos o país. A partir da criação dessa nova categoria - filme livre -, a MFL tornou visível ao circuito cinematográfico um conjunto de produções e autores que poucas pessoas imaginavam existir. Para o criador da mostra, Guilherme Whitaker ${ }^{21}$, um "filme livre" seria uma produção ousada, que busca alternativas em sua linguagem, que procura inovar de alguma forma que escape aos padrões televisivos e do cinema comercial, uma vez que estes já possuem seus espaços. Mas, seria também um “cinema possível”, aquele que se faz na paixão e na guerrilha, com o que se tem no momento.

Atualmente, a MFL tem duração de 3 meses, ocorre nas cidades do Rio de Janeiro, São Paulo e Brasília, e aceita longas, longuíssimos, médios, curtas, curtíssimos e "pílulas"22. Suas categorias incluem filmes feitos em escolas e oficinas de audiovisual. No que concerne à produção popular de audiovisual, isso é muito relevante, pois estes espaços são a porta de entrada de muitos jovens das periferias e favelas no mundo do cinema e, também, acabam funcionando como parceiros para os filmes que os jovens seguem fazendo, mesmo depois do curso. É comum que um grupo de ex-alunos permaneça ainda ligado à instituição e a tenha como um importante apoio em suas primeiras produções individuais.

Junto com a exibição das produções, os festivais possibilitam a promoção não só dos filmes, mas também das equipes, pois além dos espectadores, mobilizam a mídia (mesmo que apenas a local) em torno do evento. Adicionalmente, isso confere visibilidade para as localidades de onde os realizadores vêm e a Baixada Fluminense, com sua participação forte e assídua nesses espaços, é um exemplo disso.

A abertura dos festivais para os filmes com baixíssmo orçamento e novos estilos, narrativas e temáticas, produzidos por grupos da periferia brasileira, começa a ressoar nos canais fechados de televisão. Trata-se, na verdade, de um processo de "confluência" - e não,

\footnotetext{
${ }^{20}$ Apenas recentemente, passou a aceitar, também, filmes realizados com algum apoio estatal, o que demonstra que alguns filmes "de guerrilha" estão começando a encontrar algum caminho de financiamento por esta via.

${ }^{21}$ Disponível em: https://www.youtube.com/watch?v=90umFU63Nz8 e MFL (2015).

${ }^{22}$ Filmes de até 3 minutos.
}

\section{POLÊM!CA $\mid$ LABORE}


necessariamente, de causa e consequência -, entre o aumento das produções por realizadores das periferias, a maior abertura dos festivais, a lei que exige a presença de audiovisual nacional nos canais de TV por assinatura ${ }^{23}$, o baixo custo dessas produções e a construção pela mídia e pelo cinema comercial (desde os anos 1980) da periferia como tema com boa bilheteria.

"Periferia" foi originalmente um termo que designava um estigma. Dentro de uma realidade urbana marcada pela segregação, definia negativamente um espaço em relação ao que ele contrastava: o "centro". Ao longo das últimas décadas, porém, o sentido de "periferia" sofreu importantes deslocamentos. Reapropriado, primeiramente, por movimentos sociais e, em seguida, por grupos artísticos e culturais locais, "periferia" passa aos poucos a ganhar uma conotação afirmativa como a marca de um pertencimento coletivo fundado no orgulho, na resistência e na criação. Na grande mídia, porém, inclusive no cinema, as periferias urbanas são, ainda, muitas vezes retratadas como espaços "outros", que podem ser tanto violentos e ameaçadores, quanto exóticos, burlescos ou kitsch. Isso devido às múltiplas "marginalidades" ali presentes para além da geográfica: a lei e ordem local marginal - desde os antigos esquadrões, passando pelas facções até as atuais milícias, assim como as ocupações marginais em seu duplo sentido, seja aquela relacionada aos espaços físicos -, invasões, posses, puxadinhos e lajes, como também a que se refere ao trabalho - o biscate, o camelô e outras tantas alternativas criativas não formalizadas. Ocorre, porém, que na fusão entre os movimentos culturais e artísticos de periferia orgulho e a sagacidade da mídia, um segundo deslocamento do termo "periferia" se constitui: a periferia fashion ${ }^{24}$.

Se o Cinema Novo trazia o olhar da intelectualidade sobre o sertão, a favela e a pobreza promovendo uma verdadeira nova onda de "filmes de cunho social" que, tanto pela temática quanto pela estética que elegeram, seriam (segundo suas crenças) capazes de emancipar os oprimidos ${ }^{25}$, de 1980 em diante, a mídia passa a estimular a periferia fashion, tendo, na visão de Prysthon e Carrero (2002), o filme Pixote como seu sintoma inicial. A exploração da temática da favela toma um novo rumo e ganha espaço no circuito cinematográfico comercial, transformando-se em boa bilheteria por tratar de um "mundo

\footnotetext{
${ }^{23}$ Lei $\mathrm{n}^{\circ} 12.485$ (Lei da TV Paga) que busca garantir a presença de mais conteúdos nacionais e independentes nos canais de TV por assinatura.

${ }^{24}$ Expressão cunhada por Phryston e Carrero (2002).

${ }^{25}$ Ver M. Fabris. O neo-realismo Italiano em seu diálogo com o cinema independente brasileiro. In: Cinemais..., p.78.
}

\section{POLÊM!CA $\mid$ LABORE}


paralelo" e até então desconhecido, que gera interesse, sedução e medo. Em seguida, ainda segundo os autores, a periferia passaria a emprestar ao cinema nacional uma certa "aura de credibilidade marginal" quando cineastas e artistas iniciantes das próprias periferias narram e encenam "suas próprias vidas", seja sob a tutela de um cineasta/produtor reconhecido como é o caso do filme 5x Favela: agora por nós mesmos, ou por conta própria, fazendo cinema na guerrilha "apenas com o que se tem".

Os filmes "de guerrilha", mas que atendam ao padrão de qualidade do canal, acabam sendo um bom negócio para as emissoras, pois contam com o interesse de espectadores e custam muito pouco. O contrato e o pequeno valor pago por um filme referem-se normalmente a licenciamento por um período de tempo e não por cada exibição, sendo que algumas vezes exigem também exclusividade. A tabela abaixo destaca o tipo e o período de veiculação dos filmes do CGB em canais de TV.

Tabela - 4: Veiculação de filmes em TV

\begin{tabular}{|l|l|l|l|}
\hline Filme & $\begin{array}{l}\text { Tipo de } \\
\text { veiculação }\end{array}$ & Canal & Período \\
\hline O Evangelista - documentário & Licenciamento & Canal Brasil & $2015-2018$ \\
\hline Gigantes da Alegria & Licenciamento & Canal Brasil & $2015-2018$ \\
\hline Vem pra Baixada! & Produção & Cine Brasil & $2014-2016$ \\
\hline
\end{tabular}

Fonte: Preparada por Tadeu Lima a partir de documentos do CGB.

Para o CGB, ter seus filmes em canais de TV não permitiu maior autonomia financeira. Para além da visibilidade, eles afirmam que a relação com os canais contribuiu para que aprimorassem a qualidade de suas produções, pois as emissoras não aceitam algumas falhas para as quais não estavam tão atentos anteriormente. Avaliam que ter que fazer uma sincronia mais perfeita entre áudio e imagem, por exemplo, entre outras coisas, acaba se constituindo em uma formação.

Assim como há uma forte relação entre a produção de filmes e os cineclubes, a relação entre quem faz filmes e a oferta de oficinas de audiovisual também é muito frequente na Baixada. No caso do CGB, as oficinas surgiram a partir de uma história triste. Quando precisaram de figuração para uma cena de briga de Caramujo e seu pé sujo, convocaram um jovem conhecido que passava na rua para o papel. Alguns meses depois, o rapaz morreu de overdose na favela do Jacarezinho ${ }^{26}$ onde morava, justo quando estavam tentando, por

${ }^{26}$ Uma das maiores favelas da cidade do Rio de Janeiro, localizada na Zona Norte.

\section{POLÊM!CA $\mid$ LABORE}


iniciativa dele, iniciar uma oficina com outros jovens de lá. Em homenagem ao rapaz, o CGB passou a oferecer oficinas de cinema no Bar do Caramujo. O público varia dos 14 aos 70 anos ou mais e, por causa das oficinas, mais pessoas começam a fazer cinema em São João de Meriti. Das turmas já saíram 5 curtas, 7 alunos já conseguiram seus registros profissionais $(\mathrm{DRTs})^{27}$ a partir das produções feitas ali, filmes da oficina foram exibidos em uma mostra no Amapá e alguns alunos passaram a integrar o CGB. Chegaram a ser contemplados com uma autorização para captarem 500 mil reais para a oficina através da Lei Rouanet ${ }^{28}$, mas como não possuem canais com empresas, não conseguiram a verba. Para que possam continuar oferecendo esta formação e emitir certificados para os participantes, planejam constituir uma ONG ou um Ponto de Cultura.

Os recursos para realizar os filmes são obtidos a partir das premiações dos festivais e outras táticas. Os prêmios que recebem em festivais giram em torno de oitocentos ou até mil reais. Algumas vezes o prêmio é algum equipamento, como foi o caso da câmera caseira que deu início à história, que podem escolher manter ou reverter em dinheiro. Outras formas de levantar dinheiro são a venda de DVD's com os filmes, além de rifas, churrascos e das oficinas que oferecem ao preço de 20 reais (embora muitos alunos façam por 5 reais ou mesmo de graça). O dinheiro do trabalho que garante o sustento de suas famílias (Ricardo no açougue, J. Ulivan no bar e Vitor atualmente fazendo vídeos em plataformas da Petrobras) é totalmente separado do orçamento do Cinema de Guerrilha por um forte motivo: a existência de uma certa "desconfiança" ou "não aprovação" por parte dos familiares de alguns com relação às suas vidas duplas de cineastas. Manter as finanças separadas foi uma saída inteligente para que o prazer de fazer filmes pudesse se realizar livre de maiores conflitos com a esfera familiar.

Toda guerrilha, infelizmente, também é feita de "baixas" e, mesmo tendo muito o que comemorar em sua trajetória, o CGB carrega outra história triste. Sua participação no filme Rio em Chamas $^{29}$ retrata um momento importante e o mais trágico desde a fundação do grupo: a morte de Fernando Silva, o Fernandão, o anão que vendia imã de geladeira e virou integrante do grupo participando como ator em vários filmes. Fernandão morreu por inalação de gás lacrimogêneo em uma manifestação de protesto politico realizada no centro da cidade

\footnotetext{
${ }^{27}$ Registro de Artista e Técnico Cinematográfico Lei no $6.533 / 78$

${ }^{28}$ Lei Federal de Incentivo à Cultura (Lei no 8.313 de 23 de dezembro de 1991) - permite que pessoas físicas e jurídicas apliquem uma parte do imposto de renda devido em ações culturais.

${ }_{29}^{29}$ Disponível em: https://vimeo.com/88130053.
}

\section{POLÊM!CA $\mid$ LABORE}


do Rio de Janeiro em 2013, no período conhecido como Jornadas de Julho. Vitor havia filmado Fernandão na manifestação e depois no hospital, antes de seu falecimento. Nesta gravação, Fernandão criticava o então governador Sérgio Cabral pela violência que havia sofrido da polícia e que culminara em seu estado grave de saúde. O vídeo foi postado no Facebook pouco antes de Fernandão morrer e em 24 horas obteve 2 milhões de compartilhamentos. As cenas gravadas por Vitor se transformaram no episódio Fernandão Vive do filme Rio em Chamas, por convite de Cavi Borges, cineasta, e Daniel Caetano, pesquisador e diretor do filme. O reconhecimento e respeito pelo trabalho do CGB fizeram com que a Mostra do Filme Livre de 2014 realizasse uma mostra/homenagem com todos os filmes de Fernandão, com curadoria de Ricardo Rodrigues.

\section{Até aqui...}

Fazer cinema no Brasil já é quase impossível. Fazer cinema de guerrilha é quase um milagre e fazer cinema de guerrilha dar certo... (Ricardo Rodrigues, em entrevista concedida para a autora).

A guerrilha, nas teorias de guerra, não é para ser algo permanente e a história não cansa de mostrar como a profissionalização acaba sendo, ao longo do tempo, o desdobramento de vários cinemas independentes, amadores, marginais. Isso não significa que se tenha perdido a guerra, uma vez que a sua entrada em um plano mais institucional não ocorre sem provocar alguma mutação, mesmo que bem discreta, no próprio campo que passa a integrar. A partir de 2012, os membros do CGB começaram a se questionar se ainda seriam "guerrilha". Hoje afirmam com convicção e alguma tristeza que não são. O equipamento hoje não é mais um celular ou uma câmera caseira, mas uma t4i e uma 60d. "Fazer filme com 60d é mole", diz Ricardo, referindo-se ao fato de que facilitam e conferem mais qualidade às produções. Mas por outro lado, sabem que estes equipamentos exigem deles um maior esmero e rigor com a luz, a fotografia, a edição, os enquadramentos, a qualidade do áudio etc.

Outro aspecto que mudou é que, agora, quando fazem um filme, existe a intenção de "lançar" e isso significa já saber que o filme vai correr muitas telas dentro e fora do país, a partir do espaço que conquistaram em mostras, festivais e cineclubes. Percebem o reconhecimento que alcançaram como algo que não pode ser apenas mantido, mas precisa ser ampliado. Por esta razão, os filmes ganharam a forma de algo que eles "assinam" e a marca CGB virou CGB Filmes, uma produtora legalmente constituída e registrada. O contexto de

\section{POLÊM!CA $\mid$ LABORE}


absoluta liberdade foi sendo aos poucos sobreposto por outro em que pesa uma responsabilidade sobre a marca "Cinema de Guerrilha da Baixada" e o nome de cada um deles.

Enquanto os meios disponíveis eram excessivamente restritos e frágeis, a margem de liberdade de ação, contrariamente, era forte. Conforme foram conquistando os meios, o reconhecimento e criando laços com instituições, a liberdade foi sendo substuitída por padrões que eles próprios passam a se autoimpor. O que não mudou até hoje foi um acordo que fizeram desde que começaram a ganhar visibilidade e circular pelo mundo. Combinaram que, sempre que forem palestrar, apresentar seus filmes ou receber prêmios em qualquer lugar, têm como compromisso falar (além de mostrar, é claro) que "na baixada não tem só pobreza, não". O Cinema de Guerrilha da Baixada ainda é isso. Sua guerrilha continua sendo bem mais do que apenas um nome.

\section{Referências}

BECKER, Howard. Art Worlds. Berkley and Los Angeles: University of Californa Press, 1982.

DIEGUES, Cacá. Vida de cinema - Antes, durante e depois do Cinema Novo. Rio de Janeiro: Objetiva, 2014.

DUBIN, Steven. The Centrality of Marginality: Naïve Artists and Savvy Supporters. In: ZOLBERG, Vera L.; CHERBO, Joni M. (ed.). Outsider Art: Contesting Boundaries in Contemporary Culture. Cambridge, England and New York: Cambridge University Press, 1997.

FINE, Gary Alan. Everyday Genius: Self-Taught art and the culture of authenticity. Chicago and London: University of Chicago Press, 2004.

FORUM DOS FESTIVAIS. Disponível em: 〈http://www.forumdosfestivais.com.br/\#!quem-somos/c1c32〉. Acesso em: 30 dez. 2016.

GUILHERME WHITAKER NO RCB NA ÍNTEGRA. Disponível em:

<https://www.youtube.com/watch?v=90umFU63Nz8>. Acesso em: 30 dez. 2016.

HB, Heraldo. O Cerol Fininho da Baixada - Histórias do Cineclube Mate com Angu. Rio de Janeiro: Aeroplano, 2013.

HEINICH, Nathalie. Outside Art and Insider Artists: Gauging Public Reactions to Contemporary Public Art. In: ZOLBERG, Vera L.; CHERBO, Joni M. (ed.). Outsider Art: Contesting Boundaries in Contemporary Culture. Cambridge, England and New York: Cambridge University Press, 1997.

KRACAUER Siegfried. Theory of Film - The redemption of physical reality. London, New York: Oxford University Press, 1960.

LAHIRE, Bernard. The Double Life of Writers. New Literary History, 2, p. 443-465, 2010.

MOSTRA DO FILME LIVRE. Catálogo. 2015.

\section{POLÊM!CA $\mid$ LABORE}

Polêmica - Revista Eletrônica da Uerj - Rua São Francisco Xavier, 524, $1^{\circ}$ andar

bloco D, sl.1001 • Tels.: +55 $212334-4088$ / 4087 • http://www.e-publicacoes.uerj.br/index.php/polemica/index http://www.labore.uerj.br • laboreuerj@yahoo.com.br 
PORTA CURTAS. Disponível em: <http://portacurtas.org.br/Default.aspx>. Acesso em: 30 dez. 2016.

PRYSTHON, Angela.; CARRERO, Rodrigo. Da periferia industrial à periferia fashion. Eco-Pós, v. 5, n. 2, p. 56-67, 2002.

RANCIÈRE, Jacques. A Noite dos Proletários - Arquivos do Sonho Operário. São Paulo: Companhia das Letras, 1988.

Le Philosophe et ses pauvres. Librarie Arthème Fayard, 1983.

RIO EM CHAMAS. Disponível em: 〈https://vimeo.com/88130053>. Acesso em: 30 dez. 2016.

ROCHA, Glauber. An Aesthetic of Hunger. In: JOHNSON, Randall; STAM, Robert (eds). Brazilian Cinema. Rutherford/Madison/Teaneck/London/Toronto: Fairleigh Dickinson University Press/Associated University Presses, 1980.

SHAVIRO, Steven. The Cinematic Body. Minneapolis: University of Minnesota Press, 1993.

Recebido em: 15/12/2016.

Aceito em: 30/12/2016.

\section{POLÊM!CA $\mid$ LABORE}

